\title{
DOUBLE BLIND RANDOMISED COMPARATIVE STUDY OF EFFICACY AND TOLERABILITY OF TELMISARTAN AND LISINOPRIL IN MALE PATIENTS OF STAGE 1 ESSENTIAL HYPERTENSION
}

\author{
R. Srinivasa Rao ${ }^{1}$, K. R. Prabhakar 2
}

${ }^{1}$ Associate Professor, Department of Pharmacology, RMC, Kakinada.

${ }^{2}$ Assistant Professor, Department of Pharmacology, KIMS, Amalapuram.

\section{ABSTRACT}

\section{OBJECTIVES}

Compare the 1. Efficacy and tolerability 2. Safety of telmisartan versus lisinopril in patients of stage-1 essential hypertension (JNC 7 classification) in study groups.

\section{MATERIAL AND METHOD}

The study was a prospective, double blind randomised comparative clinical trial. Male patients aged between 20 to 65 years attending medicine 0/P Department in the Government General Hospital, Kakinada, were selected for this study, prior permission was also taken from the institution ethics committee of Rangaraya Medical College, Kakinada to conduct the study.

A total of 60 male patients with stage- 1 essential hypertension were enrolled in the study as per the selection criteria. Group T patients received $40 \mathrm{mg}$ of telmisartan/Group L patients received lisinopril 10mg once a day orally for 12 weeks. Investigations and BP taken periodically throughout study period.

\section{RESULTS}

The mean reduction in systolic BP/diastolic BP in the telmisartan/lisinopril group at the end of the study, i.e., after 12 weeks was $14.93 \pm 3.85 / 14.40 \pm 3.46 \mathrm{mmHg}$ and $10.20 \pm 1.77 / 9.47 \pm 2.29 \mathrm{mmHg}$. When two groups was compared there was no significant difference between the groups $(\mathrm{P}>0.05)$.

The frequency of adverse effects between the groups was not statistically significant $(P>0.05)$. However, in lisinopril treated group the incidence of dry cough was significantly higher compared to telmisartan group $(\mathrm{P}<0.05)$.

\section{CONCLUSION}

The results from this study demonstrate that telmisartan is as effective as lisnopril for treatment of patients with stage 1 hypertension. Treatment with telmisartan was associated with decreases in blood pressure at the end of the study that was similar to that with the ACE inhibitor lisinopril. In lisinopril treated group, the incidence of dry cough was significant.

\section{KEYWORDS}

In Male Patients Stage 1 Essential Hypertension, Telmisartan and Lisinopril.

HOW TO CITE THIS ARTICLE: R. Srinivasa Rao, K. R. Prabhakar. "Double Blind Randomised Comparative Study of Efficacy and Tolerability of Telmisartan and Lisinopril in Male Patients of Stage 1 Essential Hypertension." Journal of Evolution of Medical and Dental Sciences 2015; Vol. 4, Issue 95, November 26; Page: 16094-16097, DOI: 10.14260/jemds/2015/2353.

\section{INTRODUCTION}

Hypertension is defined conventionally as a sustained increase in blood pressure $\geq 140 / 90 \mathrm{mmHg}$, a criterion that characterizes a group of patients whose risk of hypertensionrelated cardiovascular disease is high enough to merit medical attention. Hypertension is a life time condition and if left untreated leads to lethal complications. $1,2,3,4$

The Renin-Angiotensin Aldosterone System (RAAS) plays an integral role in the homeostatic control of arterial pressure, tissue perfusion, and extracellular volume. Three classes of drugs act specifically on the renin-angiotensin system.

Financial or Other, Competing Interest: None.

Submission 23-10-2015, Peer Review 24-10-2015,

Acceptance 18-11-2015, Published 26-11-2015.

Corresponding Author:

Dr. R. Srinivasa Rao,

Associate Professor

Department of Pharmacology,

RMC, Kakinada.

E-mail:dr.rsrking@gmail.com

DOI:10.14260/jemds/2015/2353.
Angiotensin converting enzyme (ACE) inhibitors, angiotensin II receptor blockers and aliskiren, an orally active renin antagonist. 5,6,7,8,9

ACE inhibitors act by reducing the biosynthesis of angiotensin II by blocking the conversion of angiotensin I by ACE, but do not inhibit non-ACE angiotensin II generating pathways. ARBs block the ATl receptor mediated actions of angiotensin II without inhibiting angiotensin II synthesis. ARBs have the advantage of blocking actions of angiotensin II from non-ACE pathways, also currently ARBs are alternative to ACE inhibitors in the treatment of essential hypertension in patients intolerable to ACE inhibitors due to adverse effects. ${ }^{10,11}$

There is constant debate over the comparative efficacy of ACE inhibitors and ARBs due to additional advantages of ARBs over ACE inhibitors. ${ }^{12}$

Hence, this study was undertaken to evaluate whether the above mentioned theoretical benefits actually translate into clinically observable benefits in patients of stage- 1 essential hypertension (jnc-7).13,14

The ACE inhibitor lisinopril and ARB telmisartan were used in the present study. 


\section{MATERIALS AND METHODS}

Male patients aged between 20 to 65 years attending medicine out-patient department in the Government General Hospital, Kakinada, were selected for this study prior permission was also taken from the institution ethics committee of Rangaraya Medical College, Kakinada to conduct the study. The study was a prospective, double blind, randomised comparative clinical trial.

A total of 60 male patients with stage-1 essential hypertension were enrolled in the study as per the selection criteria. They were randomly allocated to two groups with 30 patients each. They were either newly diagnosed or who have discontinued antihypertensive medication voluntarily for more than 4 weeks.

The following categories of patients were excluded from the study: Patients on other antihypertensive therapy, patients of secondary hypertension, patients with impaired liver function defined as SGOT or SGPT $>2$ times the normal limit, patients with impaired kidney function defined as serum creatinine $>2 \mathrm{mg} / \mathrm{dl}$, female patients, patients with history suggestive of obstructive biliary disease, cholestasis or severe hepatic impairment.

After fulfilling the inclusion and exclusion criteria, the patients were enrolled into the study and informed written consent was obtained from all patients after a detailed explanation prior to enrolment. Current medical history and diagnosis were noted during the first visit. The patients were randomly allocated to receive either telmisartan or lisinopril with 30 patients in each group.

Group T patients received $40 \mathrm{mg}$ of telmisartan once a day orally for 12 weeks while Group L patients received lisinopril 10mg once a day orally for 12 weeks.

The patients were followed for every 2 weeks throughout the study period, i.e., at 2 weeks, 4 weeks, 6 weeks, 8 weeks, 10 weeks, 12 weeks. Compliance of the patient regarding medication consumption is assessed by the pill count method where 18 pills were given at each visit every 2 weeks. The patient has to show the remaining four tablets.

At each visit complete clinical examination was carried out including a recording of systolic and diastolic blood pressure of each patient using a mercury sphygmomanometer by the auscultation method. The BP was recorded in sitting position after 10 min of rest.15,16

Investigations such as hemogram (Hb, TLC), serum creatinine, SGOT, SGPT, random blood sugar and urine examination were performed during the first visit and 12 weeks of the study period.

The statistical analysis was done using the unpaired student's ' $t$ ' test for comparing the quantitative data of the two study groups. A P-value $<0.05$ was taken as significant and P-value $<0.001$ was taken as highly significant, while $\mathrm{P}>0.05$ was considered as insignificant.

\section{RESULTS \\ REDUCTION IN SYSTOLIC BLOOD PRESSURE WITH EACH DRUG}

In the telmisartan treated group, the mean systolic BP prior to treatment was $145.80 \pm 5.52 \mathrm{mmHg}$. After treatment, the mean systolic BP reduced to $130.87 \pm 6.07 \mathrm{mmHg}$, i.e., at
12 weeks. The reduction in systolic BP after 12 weeks was found to be statistically significant $(\mathrm{P}<0.001)$ when compared with the baseline readings.

In the lisinopril treated group, the mean systolic BP prior to treatment was $146.67 \pm 5.34 \mathrm{mmHg}$. After treatment, the mean systolic BP reduced to $132.27 \pm 5.11 \mathrm{mmHg}$ i.e., at 12 weeks. The reduction in systolic BP after 12 weeks was found to be statistically significant $(\mathrm{P}<0.001)$ when compared with the baseline readings. ${ }^{17,18,19,20}$

\begin{tabular}{|c|c|c|}
\hline $\begin{array}{c}\text { FALL IN SBP } \\
\text { (mmH) }\end{array}$ & LISINOPRIL & TELMISARTAN \\
\hline MAX & 20 & 20 \\
\hline MIN & 10 & 10 \\
\hline MEAN & 14.40 & 14.93 \\
\hline SD & 3.46 & 3.85 \\
\hline \multicolumn{2}{|c|}{ Table 1: The Reduction in Systolic BP After 12 Weeks } \\
\hline
\end{tabular}

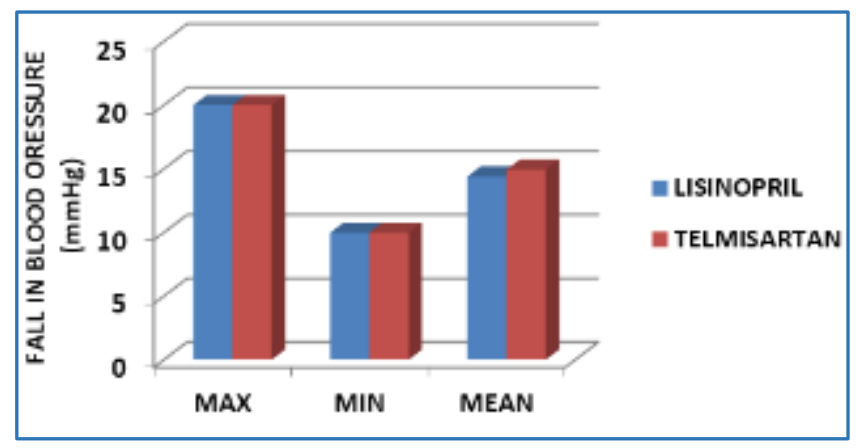

Fig. 1:Fall in Systolic Blood Pressure

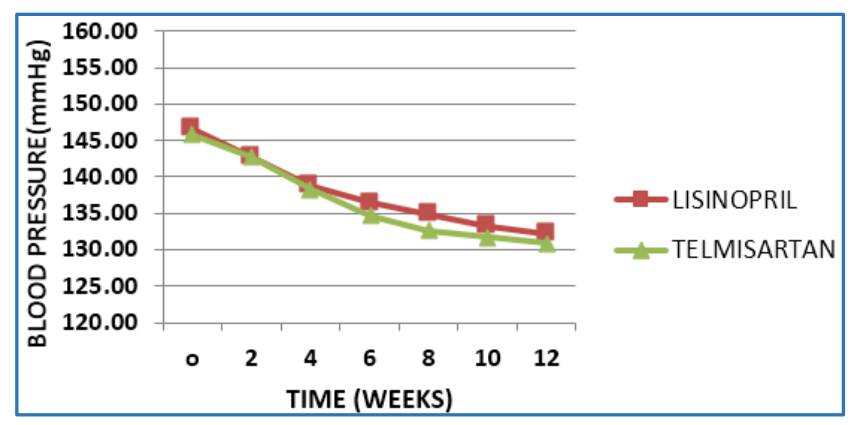

Fig. 2: Fall in Systolic Blood Pressure

In the present study, the mean reduction in systolic blood pressure after completion of the study in telmisartan group is $14.93 \pm 3.85 \mathrm{mmHg}$ with no significant difference ( $>0.05$ ) compared to lisinopril group mean reduction in systolic blood pressure of $14.40 \pm 3.46$.

\section{REDUCTION IN DIASTOLIC BLOOD PRESSURE WITH EACH DRUG}

The mean diastolic BP before telmisartan treatment was $91.33 \pm 3.17 \mathrm{mmHg}$. At the end of the study after 12 weeks, the mean diastolic BP reduced to $81.13 \pm 2.76 \mathrm{mmHg}$. The reduction in diastoilc $\mathrm{BP}$ after 12 weeks was found to be statistically significant $(\mathrm{P}<0.001)$ when compared with the baseline readings.

The mean diastolic BP before lisinopril treatment was $91.47 \pm 3.10 \mathrm{mmHg}$. At the end of the study after 12 weeks, the mean diastolic BP reduced to $82.00 \pm 2.83 \mathrm{mmHg}$. The 
reduction in diastolic $\mathrm{BP}$ after 12 weeks was found to be statistically significant $(\mathrm{P}<0.001)$ when compared with the baseline readings.

\begin{tabular}{|c|c|c|}
\hline $\begin{array}{c}\text { FALL IN DBP } \\
\text { (mmHg) }\end{array}$ & LISINOPRIL & TELMISARTAN \\
\hline MAX & 14 & 16 \\
\hline MIN & 4 & 6 \\
\hline MEAN & 9.47 & 10.20 \\
\hline SD & 2.29 & 1.77 \\
\hline \multicolumn{2}{|c|}{ Table 2: The Reduction in Diastolic BP After12 Weeks } \\
\hline
\end{tabular}

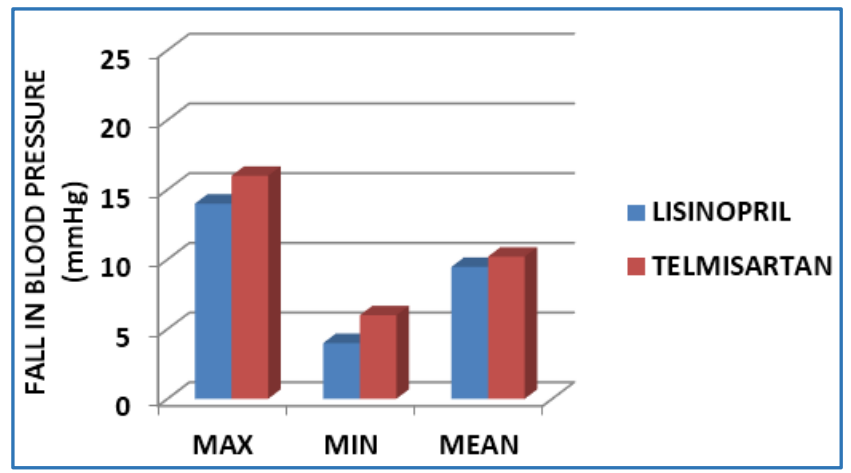

Fig. 3: Fall in Diastolic Blood Pressure

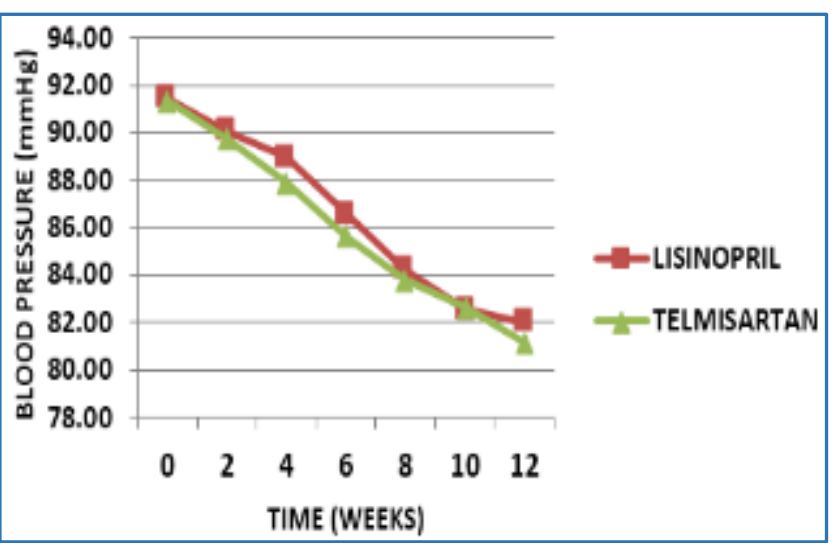

Fig. 4: Fall in Diastolic Blood Pressure

In the present study, the mean reduction in diastolic blood pressure after completion of the study in telmisartan group is $10.20 \pm 1.77$ with no significant difference $(p>0.05)$ compared to lisinopril group mean reduction in diastolic blood pressure of $9.47 \pm 2.29$.

\begin{tabular}{|c|c|c|}
\hline SIDE EFFECT & LISINOPRIL & TELMISARTAN \\
\hline HEADACHE & 3 & 2 \\
\hline DIZZINESS & 3 & 3 \\
\hline FATIGUE & 0 & 3 \\
\hline NAUSEA & 2 & 2 \\
\hline DRY COUGH & 7 & 0 \\
\hline HYPOTENSION & 0 & 0 \\
\hline \multicolumn{2}{|r|}{ Table 3: Occurrence of Side Effects } \\
\hline
\end{tabular}

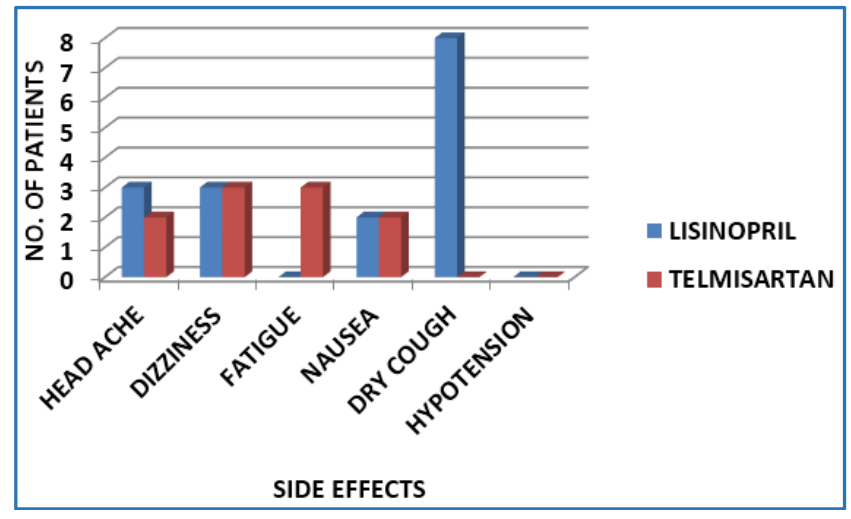

Fig. 5: The Frequency of Adverse Effects Between the Groups

- In the total study, headache is seen in $7 \%$ two patients in telmisartan group and $10 \%$ three patients in lisinopril group.

- Dizziness is seen in $10 \%$, three patients in each group.

- Fatigue is seen in $10 \%$, three patients in telmisartan group only.

- $\quad$ Nausea is seen in 7\%, two patients in each group.

- Dry cough is seen in $23 \%$, seven patients in lisinopril group only.

- Hypotension is not seen in either group.

The frequency of adverse effects between the groups was not statistically significant $(\mathrm{P}>0.05)$. However, in lisinopril treated group the incidence of dry cough was significantly higher compared to telmisartan group $(\mathrm{P}<0.05)^{21,22,23}$

\section{DISCUSSION}

Hypertension is one of the leading causes of the global burden of disease. Hypertension doubles the risk of cardiovascular diseases including Coronary Heart Disease (CHD), Congestive Heart Failure (CHF), ischemic and hemorrhagic stroke, renal failure, and peripheral arterial disease. Although antihypertensive therapy clearly reduces the risks of cardiovascular and renal disease, large segments of the hypertensive population are either untreated or inadequately treated.

The present study is a double blind randomized study comparing telmisartan $(40 \mathrm{mg})$ and lisinopril $(10 \mathrm{mg})$ in male patients with stage 1 essential hypertension. The principal aim was to study efficacy and tolerability of both the drugs and compare them.

In the present study, the maximum number of patients that is $77 \%$ of the total study group were in the age group 51 65 years. The remaining 23\% patients were in the age group 31-50 years with no patients in the lower age group that is 18-30 years.

The present study constituted of $100 \%$ male patients with stage 1 essential hypertension.

The mean reduction of systolic blood pressure with telmisartan is $14.93 \pm 3.85 \mathrm{mmHg}$ with no significant difference $(p>0.05)$ compared to lisinopril group mean reduction in systolic blood pressure of $14.40 \pm 3.46$. This shows that there was no significant difference in the mean reduction of systolic blood pressure between the two groups. 
The mean reduction in diastolic blood pressure after completion of the study in telmisartan group is $10.20 \pm 1.77$ with no significant difference ( $p>0.05$ ) compared to lisinopril group mean reduction in diastolic blood pressure of $9.47 \pm 2.29$. This shows that there was no significant difference in diastolic blood pressure reduction between the two groups.

The side effects caused by both the drugs were almost similar. In the total study head ache is seen in 7\% (2) patients in telmisartan group and 10\% (3) patients in lisinopril group.

Dizziness is seen in $10 \%$ (3) patients in each group. Fatigue is seen in $10 \%$ (3) patients in telmisartan group only. Nausea is seen in 7\% (2) patients in each group. Dry cough is seen in 23\% (7) patients in lisinopril group only. Hypotension is not seen in either groups.

Similar results were shown by a meta-analysis of randomised controlled trials of telmisartan versus lisinopril in the treatment of hypertension by Department of Anaesthesiology, Changzheng Hospital, Shanghai. ${ }^{23}$

The present study showed that both telmisartan and lisinopril are effective drugs in reducing both systolic and diastolic blood pressure throughout study period when measured at the $2^{\text {nd }}, 4^{\text {th }}, 8^{\text {th }}, 10^{\text {th }}$, and $12^{\text {th }}$ week. When efficacy of telmisartan is compared with lisinopril, it showed that there was no statistical difference in Systolic Blood Pressure (SBP) and Diastolic Blood Pressure (DBP) reduction between telmisartan and lisinopril. ${ }^{24,25}$

In the present study when tolerability is compared between telmisartan and lisinopril the overall frequency of adverse effects was similar, but in lisinopril group the incidence of dry cough was higher as compared to that in telmisartan group $(23 \%$ and $0 \%$ respectively, $\mathrm{p}<0.05)$.

\section{BIBLIOGRAPHY}

1. Ludovit Paulis and Thomas Unger. Novel therapeutic targets for hypertension. Nature reviews |cardiology volume 7| August 2010;431-439.

2. Cranemg, Harris JJ. Effect of aging on renin activity and aldosterone excretion. J Lab Clin Med 1976;87:947-959.

3. Genest J, Larochelle P, Cussan JR, et al. The atrial natriuretic factor in hypertension. Hypertension 1988;11(Suppl. I ):1-3.

4. Gribbin B, Pickering TG, Sleight P, et al. Effect of age and high blood pressure on baroreflex sensitivity in man. $p$. 424-431.

5. Hypertension in the elderly. Sowers JR, Am J Med 198;82 p.1-8.

6. Kotchen TA, McCarron DA. Dietary electrolytes and blood pressures: A statement for healthcare professionals from the American Heart Association Nutrition committee. Circulation 1998;98P:613-617.

7. Pudley IB, Beilin LJ, Vandongen R. Regular alcohol use raises blood pressure in treated hypertensive subjects. A Randomised Controlled Trail. Lancet 1987;p.647-651.

8. Nava E Luscher TF. Endothelium derived vaso active factors in hypertension; 13 supplement ps39-s48.

9. Luscher TF. The endothelium in hypertension. j HYPERTENS 1994;12(suppl). P. S105-116.
10. Cardillo C, Kilcoyne CM, Quyyumi et al. A selective defect in nitric oxide synthase may explain the impaired endothelium dependent vasodilatation. P 851-6.

11. Steven A. Atlas, MD. The Renin-Angiotensin Aldosterone System: Pathophysiological Role and Pharmacologic Inhibition. Supplement to Journal of Managed Care Pharmacy JMCP/October 2007/Vol. 13, No. 8. p. S9-S20.

12. Weidmann P, D.E. Myttenaere, Smaxwell MH et al. Effect of aging on plasma rennin aldosterone in normal men. Kidney int 1975;P325-333.

13. The seventh report of the Joint National Committee on prevention, Detection, Evaluation, and Treatment of High Blood Pressure: The JNC 7 Report. JAMA.

14. Guidelines subcommittee, World Health OrganisationInternational society of hypertension guidelines for the management of hypertension. j hypertens 1999;17:P.151-183.

15. Perloff D, Grim C, Flack J et al. Human blood pressure determination by sphygomanometry [AHA Medical/Scientific Statement]. special report. Circulation 1993;88:p2460-2470.

16. Effect of aging on rennin activity and aldosterone excretion. Cranemg, Hariss JJ. J Lab Clin Med 1976;87:p947-959.

17. Reference card from the Seventh Report of the Joint National Committee on Prevention, Detection, Evaluation, and Treatment of High Blood Pressure (JNC 7).

18. Aram. V. Chobnanian. The hypertension paradox more uncontrolled disease despite improved therapy. NEJM, 2009;361:p878-879.

19. British hypertension society. Drug classes. Angiotensinconverting enzyme inhibitors. Final Copy Dec 2008.

20. Angiotensin-converting enzyme inhibitors. A Position Statement of the NSW Therapeutic Assessment Group Inc. 1994.

21. Z H Israili. Journal of human hypertension. Clinical pharmacokinetics of angiotensin II $\left(\mathrm{AT}_{1}\right)$ receptor blockers in hypertension. April 2000; Volume 14, Supplement 1: Pages S73-S86.

22. David H.G. Smith. Comparision of Angiotensin II type I receptor antagonists in the treatment of hypertension. Integrium, Tustin, California, USA. 2008 Adis Data Information BV.

23. Zou Z, Xi GL, Yuan HB, Zhu QF, Shi XY. Telmisartan versus angiotension-converting enzyme inhibitors in the treatment of hypertension: a meta-analysis of randomized controlled trials Journal of human hypertension(2008);P1-11.

24. Telmisartan-Medscape reference. Available from URL: http://reference.medscape.com/drug/micardistelmisartan-342322\#4.

25. William B. White, MD. Comparative effects of telmisartan in the treatment of hypertension. The Journal of clinical hypertension. supplement 1 vol. iv no. iv July/August 2002;P20-25. 